\title{
Flora da Bahia: Krameriaceae
}

\section{Moabe Ferreira Fernandes ${ }^{1 *}$, Ana Maria Giulietti ${ }^{1,2, a}$, Reyjane Patrícia de Oliveira ${ }^{1, b}$ \& Carla Teixeira de $\operatorname{Lima}^{1, c}$}

${ }^{1}$ Programa de Pós-Graduação em Botânica, Universidade Estadual de Feira de Santana, Bahia, Brasil.

${ }^{2}$ Royal Botanic Gardens, Kew, Reino Unido.

\begin{abstract}
Resumo - Este levantamento florístico de Krameriaceae é uma contribuição ao projeto Flora da Bahia. Foram reconhecidas quatro espécies do gênero Krameria: K. argentea, K. bahiana, K. grandiflora e K. tomentosa. São apresentadas descrições e ilustrações, além de comentários gerais para os táxons e uma chave de identificação.
\end{abstract}

Palavras-chave adicionais: Brasil, florística, Krameria, taxonomia.

\begin{abstract}
Flora of Bahia: Krameriaceae) - This account of the Krameriaceae is a further contribution to the ongoing Flora of Bahia project. Four species are recognized in the genus Krameria: K. argentea, K. bahiana, K. grandiflora, and K. tomentosa. Descriptions and illustrations as well as general comments for the taxa and a key for identification are presented.
\end{abstract}

Additional key words: Brazil, floristics, Krameria, taxonomy.

\section{KRAMERIACEAE}

Krameria Leofl.

Arbustos geralmente bem ramificados, ou ervas perenes, decumbentes, hemiparasitas, com folhas verdes ou castanhas, geralmente com indumento estrigoso ou tomentoso, dourado ou alvescente. Folhas alternas, espiraladas ou dísticas, simples ou trifolioladas, margem inteira, sésseis ou pecioladas, sem estípulas. Inflorescência terminal ou axilar, racemosa ou flor solitária, 1 bráctea e 2 bractéolas por flor. Pedicelo não articulado, quando as duas bractéolas emergem na base, ou articulado, quando as bractéolas emergem acima da base. Flores bissexuadas, zigomorfas; sépalas 4 (1 adaxial, 1 abaxial e 2 laterais), geralmente similares, petaloides, pubescentes; pétalas 5, dimórficas, 2 abaxiais modificadas em glândulas secretoras, posicionadas em cada lado do ovário, 3 adaxiais livres ou conatas na base ou até $3 / 4$ inferiores, estreitamente oblanceoladas, lineares ou lanceoladas, com ápice acuminado, agudo ou obtuso; estames (3)4, livres ou geralmente conatos, adnatos às pétalas adaxiais, anteras poricidas; ovário súpero, 2-carpelar, hirsuto, glabro ou piloso, estilete 1. Fruto noz, raramente cápsula com deiscência irregular, globoso ou cordiforme, exocarpo com espinhos longos ou curtos, espinhos lisos ou providos de gloquídeos (cerdas retrorsas), com ou sem tricomas. Semente 1, endosperma reduzido.

Krameriaceae é uma família monofilética que inclui apenas o gênero Krameria, com 18 espécies, e está incluída na ordem Zygophyllales (APG III 2009). Na lista da Flora do Brasil, são citadas cinco espécies (Simpson 2010), quatro ocorrendo no estado da Bahia.

\footnotetext{
*Autor para correspondência: moabeffernandes@hotmail.com;

aanagiulietti@hotmail.com; breyjanepatricia@hotmail.com;

ccarlabotanica@yahoo.com.br

Editor responsável: Pedro Fiaschi

Submetido: 17 jul. 2013; aceito: 29 mar. 2014

Publicação eletrônica: 15 ago. 2014; versão final: 22 ago. 2014
}

\section{Chave para as espécies}

1. Ovário e fruto glabros ou glabrescentes; fruto com muitos espinhos, quase se tocando na base, sem gloquídeos

1. K. argentea

1'. Ovário e fruto pubescentes; fruto com espinhos esparsos, separados entre si na base por áreas pubescentes, com gloquídeos e tricomas.

2. Fruto com 14-30 espinhos; tricomas estendendo-se até $2 / 3$ acima da base de cada espinho .................................. 3. K. grandiflora

2'. Fruto com mais de 50 espinhos; tricomas somente na base dos espinhos.

3. Pedicelo não articulado; bractéolas inseridas na base do pedicelo; sépalas adaxial e abaxial maiores que as laterais; pétalas adaxiais livres, com ápice acuminado; estames isodínamos ............... 2. K. bahiana

3'. Pedicelo articulado; bractéolas inseridas acima da base (até $1 / 2$ ) do pedicelo; sépalas adaxial e abaxial quase do mesmo tamanho que as laterais; pétalas adaxiais conatas, com ápice agudo; estames didínamos

4. K. tomentosa

1. Krameria argentea Mart. ex Spreng., Syst. Veg. (ed. 16) 2: 844. 1825.

Figuras $1 \mathrm{~A}-\mathrm{G}$ e 2 .

Arbustos eretos, até $1 \mathrm{~m}$ alt.; ramos densamente tomentosos. Folhas ovais a lanceoladas, $24-30 \times 7-11$ $\mathrm{mm}$, pecíolo 3-7 $\mathrm{mm}$ compr.; lâmina com tonalidade prateada, ápice acuminado ou mucronado, base aguda, lanosa em ambas as faces, com 2 nervuras. Flores róseas a vináceas, pedicelo articulado, 4-7 mm compr., bractéolas lineares, $2-3 \times$ ca. $1 \mathrm{~mm}$; sépalas ovais, tomentosas na face abaxial, mais densamente na porção central, $8-10 \times 4,8-5 \mathrm{~mm}$; pétalas adaxiais $5,1-6 \mathrm{~mm}$ compr., estreito-oblanceoladas, conatas, ápice agudo, as abaxiais $3,1-3,5 \times 2,2-2,8 \mathrm{~mm}$, obdeltoides; estames 4 , didínamos, filetes do par maior 4,5-5,5 mm compr., filetes do par menor $3-4,5 \mathrm{~mm}$ compr.; 
gineceu 4,5-5,1 $\mathrm{mm}$ compr., ovário glabro, com espinhos, estilete 2,5-3 mm compr. Frutos globosos, 4-6,5 mm diâm. (excluindo espinhos), glabros ou glabrescentes, muitos espinhos de 2-3 mm compr., densamente dispostos, com as bases quase se tocando, sem gloquídeos.

A espécie é endêmica do Brasil, ocorrendo principalmente nos estados de Goiás, Minas Gerais e Bahia (Simpson 1989, 2010). D1, E2, F5: cerrado, no oeste e sudoeste da Bahia. Floresce e frutifica de outubro a maio.

Material selecionado - Barreiras, $11^{\circ} 37^{\prime} 18^{\prime \prime} \mathrm{S}, 46^{\circ} 02^{\prime} 30^{\prime \prime} \mathrm{W}$, 770 m s.n.m., s.d. (fl.). A. Cotrim et al. 145 (HUEFS); Érico Cardoso, Vereda, estrada Morro do Fogo, 1315'55"S, 42 06'22"W, 1093 m s.n.m., s.d. (fl., fr.), T. Ribeiro et al. 319 (HUEFS); Macaúbas, Poço da Anta, 26 out. 2004 (bot., fl., fr.), G. Hatschbach et al. 78588 (MBM); São Desidério, próximo à Ilha do Vitor, 679 m s.n.m., 12³9'54"S, 4502'00”'W, 22 maio 2010 (bot., fl., fr.), E. Melo et al. 8182 (HUEFS).

A espécie é bem distinta das demais que ocorrem na Bahia, e pode ser reconhecida pelas folhas com tonalidade prateada e duas nervuras laterais conspícuas em ambas as faces, além do ovário glabro, com pequenos espinhos, e dos frutos com muitos espinhos e sem gloquídeos.

2. Krameria bahiana B.B.Simpson, Brittonia 39: 198. 1987.

Figuras $1 \mathrm{H}-\mathrm{N}$ e 2.

Ervas ou subarbustos decumbentes, até $1 \mathrm{~m}$ alt.; ramos glabros ou com tricomas esparsos. Folhas lanceoladas a ovais, $8-28,5 \times 1,5-9,5 \mathrm{~mm}$, pecíolo $2-8$ $\mathrm{mm}$ compr.; lâmina esverdeada, ápice agudo ou mucronado, pilosa em ambas as faces. Flores róseas a vermelhas, pedicelo não articulado, 5-8 mm compr., bractéolas inseridas na base do pedicelo, lineares, 1,7$3 \times$ ca. $1 \mathrm{~mm}$; sépalas lanceoladas, tomentosas na face abaxial, mais densamente na porção central, a adaxial e a abaxial 9-13 × 4,5-5,5 $\mathrm{mm}$, as laterais 6-7 × 3-4 $\mathrm{mm}$; pétalas adaxiais 7-9 $\mathrm{mm}$ compr., estreitooblanceoladas, livres entre si, ápice acuminado, as abaxiais 3-4 × 2,2-3,5 mm, obdeltoides; estames 4 , isodínamos, 6-7,5 $\mathrm{mm}$ compr.; gineceu 6-8 $\mathrm{mm}$ compr., ovário tomentoso, com espinhos, estilete 4-4,5 $\mathrm{mm}$ compr. Frutos globosos, 4,5-5,5 mm diâm. (excluindo espinhos), pubescentes, muitos espinhos de 3-4 mm compr., com gloquídeos do ápice até a porção mediana.

A espécie é endêmica da Bahia. Segundo Simpson (1989, 2010), ocorre nos domínios Caatinga, Cerrado e Mata Atlântica. C6, D6, E8, E9, F6: campo rupestre e restinga. Floresce e frutifica de fevereiro a novembro.

Material selecionado - Abaíra, Catolés, Serra da Tromba, encosta da Serra do Atalho, 1.350 m s.n.m., 18 jun. 1992 (bot., fl., fr.), W. Ganev. 520 (HUEFS); Camaçari, Arembepe, condomínio Laguna. 1256'S, $38^{\circ} 21^{\prime} \mathrm{W}, 3$ fev. 2006 (bot., fl., fr.), D. Cardoso et al. 1022 (HUEFS); Entre Rios, sudoeste do povoado de Subaúma, 24 mar. 1995 (bot., fl., fr.). F. França et al. 1125 (HUEFS); Jandaíra, fazenda INVISA, 25 jul. 2011 (bot., fl.), E.N. Matos et al.
226 (HUEFS); Mata de São João, Imbassaí, 12²8’28”'S, 3757’43”, 36 m s.n.m., 18 nov. 2005 (bot., fl., fr.), A.K.A. Santos et al. 486 (HUEFS); Morro do Chapéu, fazenda Formosa,

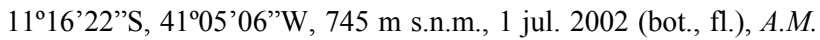
Giulietti et al. 2138 (HUEFS); Piatã, Jambeiro-Cravada, Serra do


Ganev. 1645 (HUEFS); Salvador, Stella Maris, condomínio Petromar, 12 ${ }^{\circ} 56^{\prime} \mathrm{S}, 38^{\circ} 21^{\prime} \mathrm{W}, 22$ fev. 1998 (bot., fl., fr.), C.B. Nascimento et al. 49 (HRB); Santo Antônio, RPPN Duna de Santo Antônio, 12²7'28”'S, 3756'14”'W, 20 ago. 2005 (bot., fl., fr.), P.L.O Rebouças 14 (HUEFS); Umburanas, Serra do Curral Frio, fazenda Licuri, $10^{\circ} 24^{\prime} 13$ "S, $41^{\circ} 18^{\prime} 42^{\prime}$ W, 908 m s.n.m., 28 maio 2010 (bot., fl., fr.), L.P. Queiroz et al. 14815 (HUEFS).

Krameria bahiana é facilmente diferenciada das outras espécies do gênero pelo porte herbáceo ou subarbustivo e decumbente, com folhas pequenas, lanceoladas e pilosas. Como sugerido por Simpson (1989), a coloração castanho-escura do material herborizado auxilia na identificação da espécie.

Krameria bahiana ocorre disjuntamente nas serras da Chapada Diamantina, em vegetação de campos rupestres, e em áreas de restinga, no domínio da Mata Atlântica, padrão de distribuição geográfica observado em várias espécies de diferentes famílias de plantas (Giulietti \& Pirani 1987). Os espécimes de restinga comumente apresentam folhas menores e lanceoladas, enquanto os espécimes dos campos rupestres possuem folhas maiores, variando de lanceoladas a ovais.

3. Krameria grandiflora A.St.-Hil., Ann. Soc. Sci. Orleáns (sér. 2) 9: 18. 1828.

Figuras $2 \mathrm{~A}-\mathrm{G}$ e 4.

Ervas ou subarbustos decumbentes, até $1 \mathrm{~m}$ alt.; ramos pilosos. Folhas lanceoladas a ovais, 8-17 × 2-8 $\mathrm{mm}$, pecíolo 1-3 mm compr.; lâmina esverdeada, ápice agudo ou mucronado, vilosa em ambas as faces. Flores róseas a vináceas, pedicelo articulado, 5-8 $\mathrm{mm}$ compr., bractéolas inseridas acima da base do pedicelo, mucronadas, 2-3,5 $\times$ ca. $1 \mathrm{~mm}$; sépalas lanceoladas, seríceas na face abaxial, 8,5-12 × 5-5,5 mm; pétalas adaxiais 6-9 $\mathrm{mm}$ compr., estreito-oblanceoladas, conatas, ápice agudo, as abaxiais 3-4,5 × 1,5-2,5 mm, oblongas; estames 4 , didínamos, filetes do par maior 4,5-6 mm compr., filetes do par menor 3,5-4 $\mathrm{mm}$ compr.; gineceu 5-6 mm compr., ovário tomentoso, com espinhos, estilete 2,5-3,4 mm compr. Frutos globosos, 3-6,5 mm diâm. (excluindo espinhos), pubescentes, 14-30 espinhos de 1-1,5 mm compr., esparsos, com gloquídeos por toda a sua extensão e tricomas estendendo-se até $2 / 3$ acima da base.

A espécie apresenta ampla distribuição, incluindo Brasil, Paraguai e Uruguai. No Brasil, ocorre nos estados do Maranhão, Piauí, Paraíba, Bahia, Mato Grosso, Goiás, Minas Gerais e Espírito Santo, nos domínios da Caatinga, Cerrado e Mata Atlântica (Simpson 1989). D5, D6, F5, G3, G4: caatingas, geralmente a até 700 m s.n.m. Floresce e frutifica de dezembro a junho. 


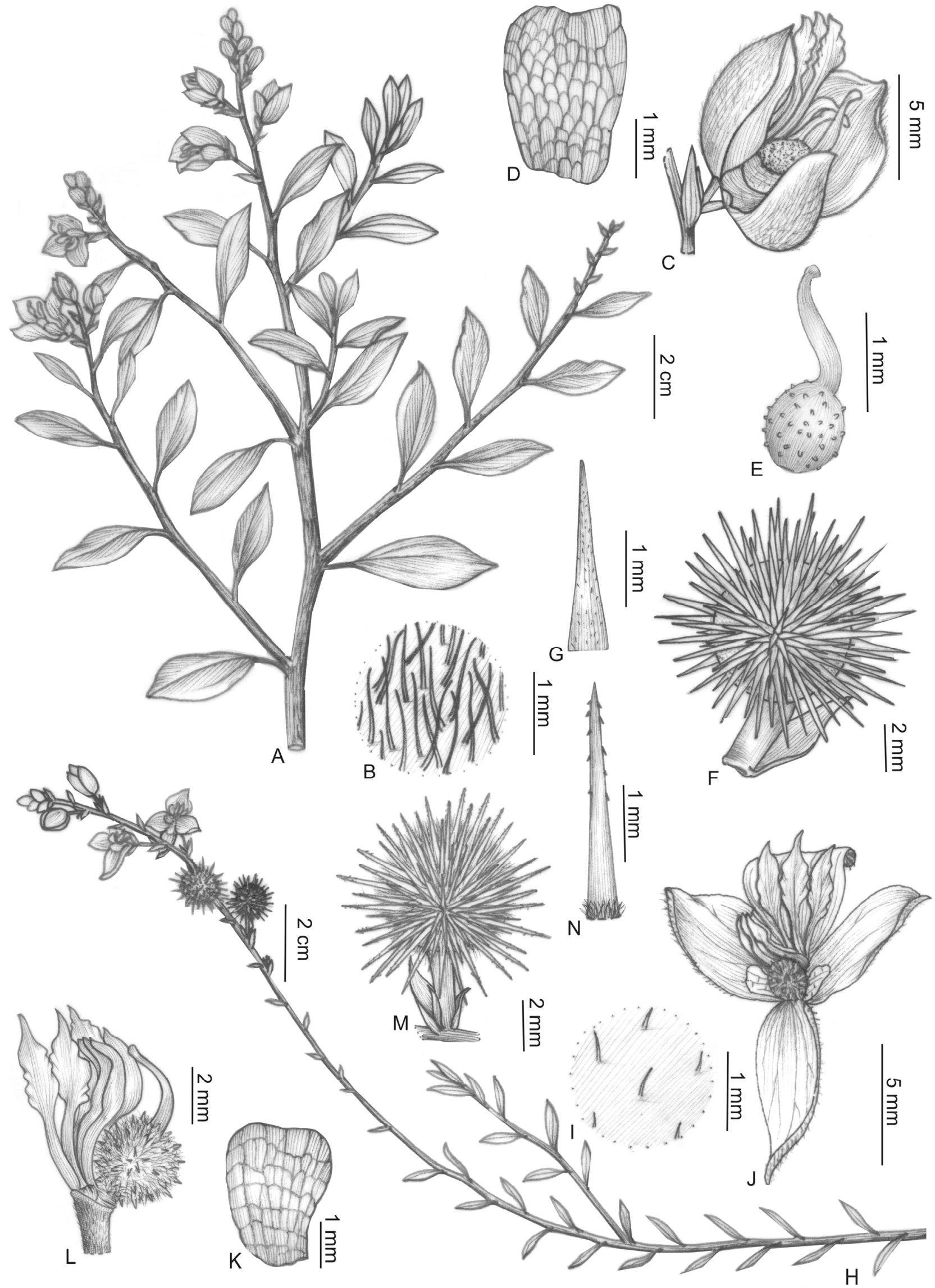

Figura 1. A-G. Krameria argentea: A- ramo com flores; B- detalhe do indumento da lâmina foliar, face abaxial; C- flor, vista lateral; Dpétala abaxial glandular; E- pistilo; F- fruto, G- espinho do fruto. H-N. Krameria bahiana: H- hábito; I- detalhe do indumento da lâmina foliar, face abaxial; J- flor, vista frontal; K- pétala abaxial glandular; L- pétalas adaxiais petaloides, androceu e gineceu; M- fruto, Nespinho do fruto (A-G- Melo 8182; H-N- Queiroz 14815). 


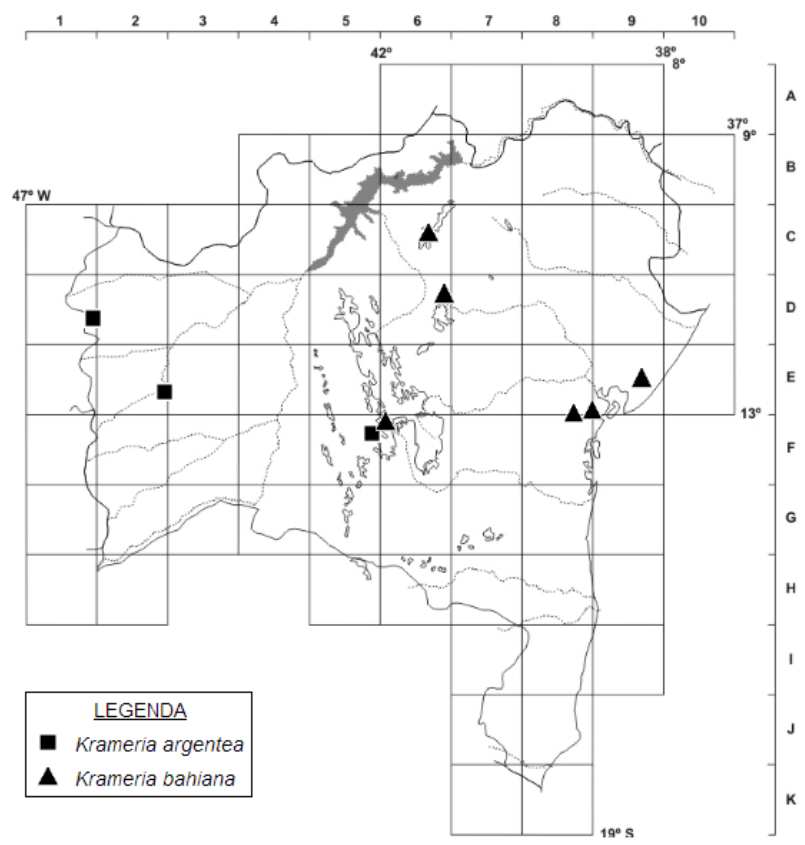

Figura 2. Distribuição de Krameria argentea e K. bahiana no estado da Bahia.

Material selecionado - Brumado, ca. $15 \mathrm{~km}$ na rodovia Brumado-Caetité, 27 dez. 1989 (bot., fl.), A.M. Carvalho et al. 2623 (CEPEC); Caetité, ca. $14 \mathrm{~km}$ ao norte da cidade em direção a Mamiaçu, 1356'03'S, 42²8'16 W, 894 m s.n.m., 14 maio 2005 (bot., fl., fr.), E.B. Miranda et al. 758 (HUEFS); Carinhanha, rodovia para a Serra do Ramalho, $10,5 \mathrm{~km}$ da sede municipal, 14²'29'S, 4345'04'W, 470 m s.n.m., 15 abr. 2001 (bot., fl.), J.G. Jardim et al. 3542 (HUEFS); Feira da Mata, Médio São Francisco,

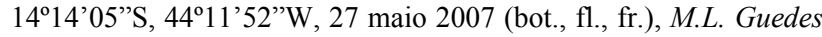
et al. 13584 (ALCB); Morro do Chapéu, Lagedo do Bordado, 690 m s.n.m., $11^{\circ} 15^{\prime} 32^{\prime}$ 'S, 4105'39'”, 19 maio 2007 (fl.,fr.), J.F.B Pastore et al. 2034 (HUEFS); Xique-Xique, Pedra Vermelha,

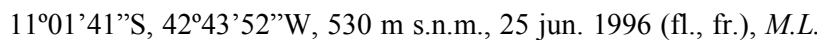
Guedes et al. 3084(ALCB).

Krameria grandiflora pode ser diferenciada das outras espécies do gênero por apresentar tricomas cobrindo até $2 / 3$ dos espinhos nos frutos. Além disso, esses espinhos são mais curtos e mais esparsos que nas outras espécies de Krameria da Bahia. Embora Simpson (1989) tenha feito referência à existência de indivíduos de $K$. grandiflora com frutos sem espinhos, esta condição não foi encontrada nos espécimes examinados da Bahia.

4. Krameria tomentosa A.St.-Hil., Ann. Soc. Sci. Orleans (sér. 2) 9: 18. 1828.

Figuras $2 \mathrm{H}-\mathrm{N}$ e 4.

Subarbustos ou arbustos eretos, até 1,5 m alt.; ramos tomentosos. Folhas lanceoladas a oblongas, 13-37,5 × 4,5-13,5 mm, pecíolo 3-8 mm compr.; lâmina esverdeada, ápice mucronado, tomentosa em ambas as faces. Flores vináceas a roxas, pedicelo articulado, 4-5 $\mathrm{mm}$ compr., bractéolas inseridas acima da base do pedicelo, lineares, 3-4 × 0,5-1 $\mathrm{mm}$; sépalas obovais, tomentosas na face abaxial, $7,1-8,5 \times$ ca. $5 \mathrm{~mm}$; pétalas adaxiais $6-7 \mathrm{~mm}$ compr., estreito-oblanceoladas, conatas, ápice agudo, as abaxiais 3,5-4 × 1,8-2,5 mm, oblongas; estames 4, didínamos, filetes do par maior 4,6-5,5 $\mathrm{mm}$ compr., filetes do par menor 3-4,3 mm compr.; gineceu 5-5,5 $\mathrm{mm}$ compr., ovário tomentoso, com espinhos, estilete 2,1-3 mm compr. Frutos globosos, 4,4-5,5 mm diâm. (excluindo espinhos), pubescentes, mais de 50 espinhos de 2-4,8 $\mathrm{mm}$ compr., densamente distribuídos, com gloquídeos do ápice até a porção mediana.

A espécie tem ampla distribuição, ocorrendo na Bolívia e no Brasil; neste último país, nos estados do Amazonas, Pará, Maranhão, Paraíba, Piauí, Bahia, Minas Gerais e Espírito Santo (Simpson 1989). B6, B8, B9, C4, C5, C6, C7, C8, C9, D2, D5, D9, D10, E8, E9, E10, F3: campo rupestre e restinga. Floresce e frutifica de janeiro a dezembro.

Material selecionado - Água Fria, estrada para a Companhia

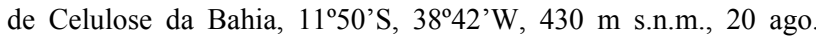
1984. (bot., fl., fr.), J.C.A. Lima \& M.M. Santos 182 (HRB); Alagoinhas, Rio Branco, fazenda de Iraci Gama, 30 set. 1988 (bot., fl., fr.), L.C.L. Lima \& N.G. Jesus 158 (HUNEBA); Aramari, fazenda Alvorada, 1200'S, 38³0'W, 252 m alt., 1 mar. 2010 (bot., fl., fr.), J.G. Carvalho-Sobrinho et al. 2731 (HUEFS); Banzaê, Área Indígena Kiriri, Baixa da Cangalha, Tanque das Nações, 1040'47'S, 38³9'47'W, 18 ago. 2002 (bot., fl., fr.), L.M. Pacheco \& C.V. Santos 23 (HUEFS); Barra, Brejo Olhos d'água, trilha ao lado da Serra, 1040'49'S, 4321'59'W, 6 nov. 2009 (bot., fl.), A.P. Prata et al. 1929 (ASE); Barreiras, próximo à Cachoeira do Acaba Vidas, 1153'13"S, 45³5'22”W, 720 m s.n.m., 12 jan. 2004 (bot., fl.), M. Machado \& M.V.M. Oliveira 72 (HUEFS); Biritinga, BR116, $4 \mathrm{~km}$ após a cidade em direção a Araci, caatinga arbustiva, solo arenoso, 18 jan. 1994 (bot., fl., fr.), M.A.S. Neves \& F.A.R. Santos 77 (HUEFS); Canudos, Reserva Biológica de Canudos, 0956'34"S, 38 59'01"W, 1 jan. 2002 (bot., fl., fr.), M.S. Castro \& C.M. Pigozzo s/n. (ALCB 66358); Casa Nova, estrada para Pau a Pique, 09²3'12'S, 41³9'48'W, 542 m s.n.m., 8 fev. 2004 (bot., fl., fr.), L.P. Queiroz et al. 9104 (HUEFS); Conde, Fazenda do Bu, Mata de São Miguel, 1203'52'S, 3741'32”W, 24 ago. 1995 (bot., fl., fr.), M.C. Ferreira \& T. Jost 758 (HRB); Dom Macedo Costa, fazenda Mocambo, 25 jul. 1972 (bot., fl., fr.), M.J.S. Lemos 49 (HUEFS); Entre Rios, Subaúma, 12º13'S 37²7'W, 8 dez. 1982 (bot., fl., fr.), A. Araújo et al. 376 (HRB); Esplanada, Dunas de Baixio, 1206'25"S, 3741'53"W, 23 abr. 2004 (bot., fl., fr.), T. Ribeiro et al. 538 (HRB); Feira de Santana, Campus da UEFS, $12^{\circ} 15^{\prime}$ 'S, 3858'W, 18 maio 1983 (bot., fl., fr.), L.R. Noblick 2656 (HRB); Gentio do Ouro, a $47 \mathrm{~km}$ da cidade, $11^{\circ} 10^{\prime} 48^{\prime \prime} \mathrm{S}$, 42'43'31'W, 7 maio 2002 (bot., fl., fr.), R. Tourinho et al. 31 (HRB); Inhambupe, 3 fev. 1981 (bot., fl., fr.), G.C.P. Pinto 26/81 (HRB); Jeremoabo, Baixa dos Quelés, 0958'59'S, 38²6'24'W, 506 m s.n.m., 17 out. 2009 (bot., fl., fr.), E. Melo et al. 6678 (HUEFS); Mata de São João, Estrada do Coco, em direção a Sauípe, 19 nov. 1981 (bot., fl., fr.), J. Arouck et al. 149 (HRB); Monte Santo, Serra do Monte Santo, 10²6'00”S, 39¹9'00'W, 31 mar. 2000 (bot., fr.), M.R. Fonseca et al. 1366 (ALCB). Paulo Afonso, Raso da Catarina, 20 set. 2008 (bot., fr.), A.A. Conceição 2995 (HUEFS); Pilão Arcado, 1004'16”S, 4250'10”W, 408 m s.n.m., 22 maio 2010 (bot., fl., fr.), L.P. Queiroz et al. 14735 (HUEFS); Pindobaçu, 1046'S 40²5'W, 10 mar. 1981 (bot., fl.), 


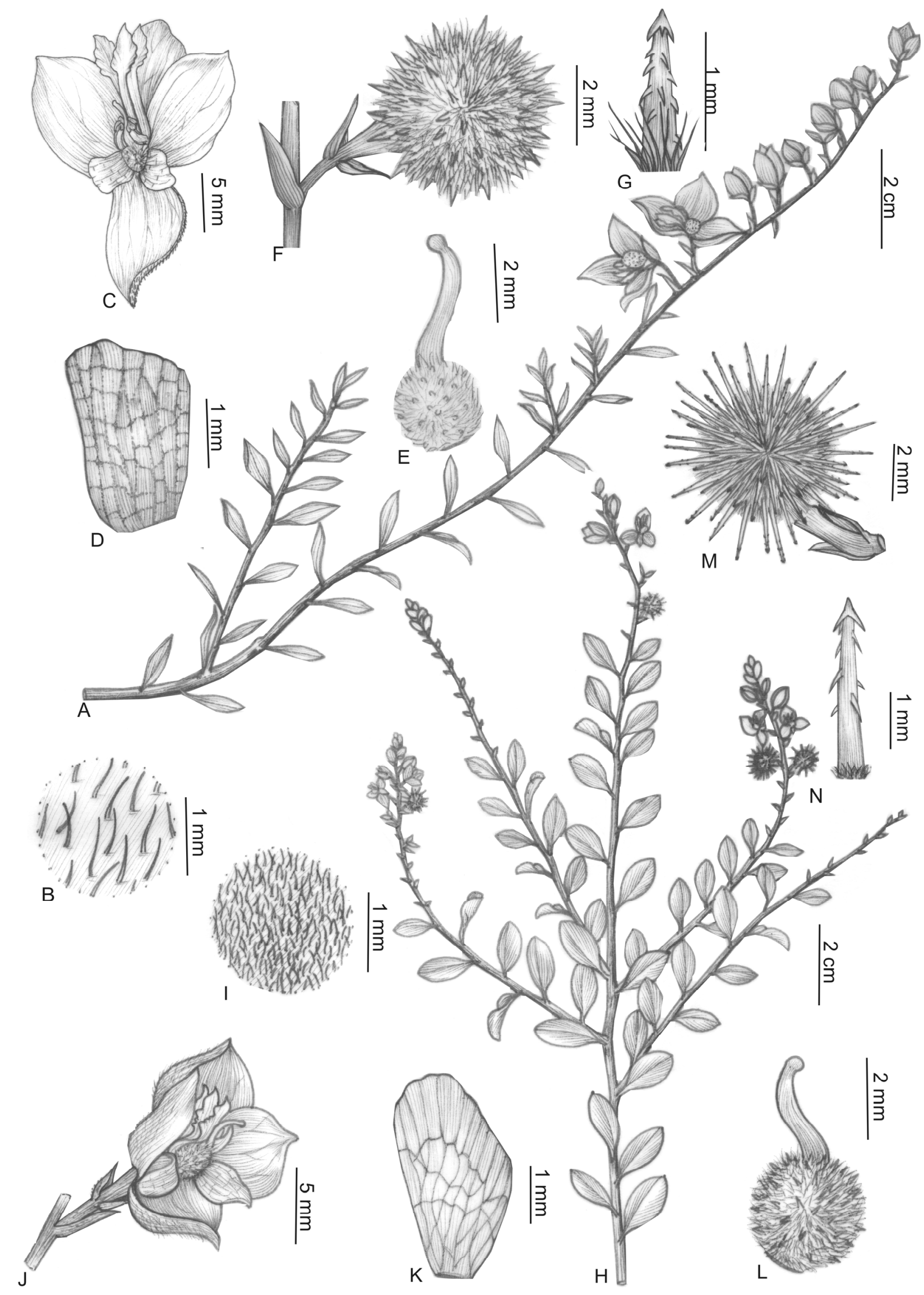

Figura 3. A-G. Krameria grandiflora: A- hábito; B- detalhe do indumento da lâmina foliar, face abaxial; C- flor, vista frontal; D- pétala abaxial glandular; E- pistilo; F- ramo com fruto, G- espinho do fruto. H-N. Krameria tomentosa: H- hábito; I- detalhe do indumento da lâmina foliar, face abaxial; J- flor, vista lateral; K- pétala abaxial glandular; L- pistilo; M- fruto, N- espinho do fruto (A-G- Miranda 758; H-N-Melo 6678). 
R.P. Orlandi 338 (HRB); Riachão das Neves, estrada para o aterro sanitário, 1346'49"S, 4454'39”W, 600 m s.n.m., 6 abr. 2005 (bot., fl.), J.G. Carvalho-Sobrinho et al. 439 (HUEFS); Salvador, Dunas de Itapoã, 10 jan. 1970 (bot., fl.), W. Santana s.n. (HRB 23366); Sento Sé, $10^{\circ} 28^{\prime} \mathrm{S} 41^{\circ} 23^{\prime} \mathrm{W}, 29$ abr. 1981 (bot., fl., fr.), R.P. Orlandi 406 (HRB); Sítio do Conde, Ilha de Restinga, Praia da Siribinha, 31 mar. 1996 (bot., fl., fr.), E.C. Medeiros Neto 4 (HUEFS); Tucano, Sítio do Mandacaru, ca. $11 \mathrm{~km}$ de Tucano, 1052'19”'S, 3846’14”'W, 382 m s.n.m., 9 abr. 2004 (bot., fl.), $D$. Cardoso 23 (HUEFS).

Krameria tomentosa é a espécie mais amplamente distribuída de Krameria na Bahia, ocorrendo em todos os domínios fitogeográficos do Estado. Apresenta grande variação foliar, tanto no tamanho quanto na forma, mas pode ser facilmente identificada em campo e no herbário por possuir as folhas tomentosas.

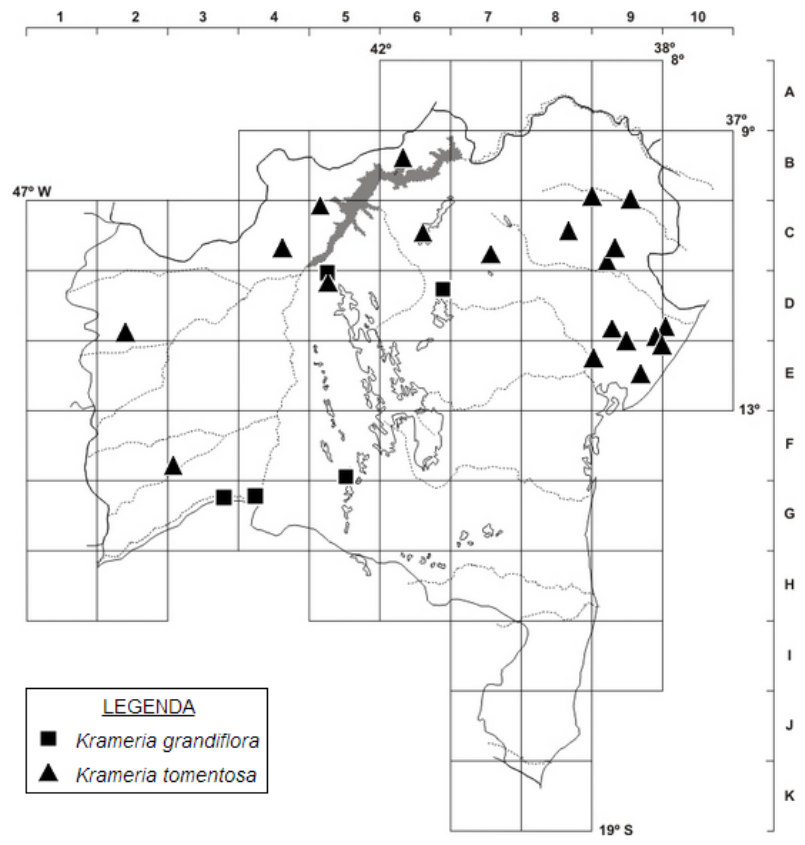

Figura 4. Distribuição de Krameria grandiflora e K. tomentosa no estado da Bahia.

\section{Agradecimentos}

Aos curadores dos herbários ALCB, ASE, CEPEC, HRB, HUEFS e HUNEBA, pelo acesso às coleções. Ao CNPq, pela bolsa de produtividade para A.M. Giulietti e R.P. Oliveira. À CAPES, pela bolsa de mestrado de M.F. Fernandes e doutorado de C.T. Lima. Ao CNPq e FAPESB, pelo financiamento aos projetos de apoio ao Flora da Bahia: FAPESB APR 162/2007; CNPq Proc. 562278/2010-9 e 483909/2012 e REFLORA Proc. 563858/2010-5. Ao Leandro Soares Pereira Lima, pela edição da prancha. Ao Pedro Fiaschi, pelas valorosas sugestões.

\section{REFERÊNCIAS}

APG III (Angiosperm Phylogenetic Group) 2009. An update of the Angiosperm Phylogeny Group classification for the orders and families of flowering plants. Botanical Journal of the Linnean Society 161: 105-121.

Giulietti, A.M. \& Pirani, J.R. 1988. Patterns of geographic distribution of some plant species from the Espinhaço Range, Minas Gerais and Bahia, Brazil. In: P. Vanzolini \& W.R. Heyer (eds), Proceedings of a Workshop on Neotropical Distribution Patterns. Academia Brasileira de Ciências, Rio de Janeiro, p. 39-69.

Simpson, B. 1989. Krameriaceae. Flora Neotropica Monograph. Vol. 49. New York Botanical Garden, New York.

Simpson, B. 2010. Krameriaceae. In: R.C. Forzza, J.F.A. Baumgratz, C.E.M. Bicudo, A.A. Carvalho Jr, A. Costa, D.P. Costa, M. Hopkins, P.M. Leitman, L.G. Lohmann, L.C. Maia, G. Martinelli, M. Menezes, M.P. Morim, M.A.N. Coelho, A.L. Peixoto, J.R. Pirani, J. Prado, L.Q. Queiroz, V.C. Souza, J.R. Stehmann, L.S. Sylvestre, B.M.T. Walter, \& D. Zappi (eds), Catálogo de Plantas e Fungos do Brasil. Vol. 1. Instituto de Pesquisas Jardim Botânico do Rio de Janeiro, Rio de Janeiro, p. 1129.

\section{Lista de Exsicatas}

Araújo, A. 376 (4); Arouck, J. 149 (4); Bautista, H.P. 808 (2); Borba, E.L. 2015 (2); Cardoso, D. 23 (4), 1022 (2); Castro, M.S. s.n ALCB 66358 (4); Conceição, A.A. 2995 (4); Carvalho, A.M. 2623 (3); Carvalho-Sobrinho, J.G. 439, 2731 (4); Cotrim, A. 145 (4); Ferreira, M.C. 758, 569, 523 (4); Fonseca, M.R. 1366 (4); França, F. 1125 (2); Ganev, W. 520, 1645 (2); Giulietti, A.M. 2138 (2); Guedes, M.L. 3084 (3), 7366 (4), 13584(3); Hatschbach, G. 486 (2); Ibrahim, M. 107 (1); Jardim, J.G. 3542 (3); Lemos, M.J.S. 49 (4); Lima, J.C.A. 182 (4); Machado, M. 72 (4); Matos, E.N. 226 (2); Medeiros Neto, E.C. 4 (4); Melo, E. 4036, 4275, 6678 (4), 8150,8182 (1), 9640 (2); Miranda, E.B. 625 (4), 758 (3); Nascimento, C.B. 49 (2); Neves, M.A.S. 77 (4); Noblick, L.R. 2656 (4); Orlandi, R.P. 160 , 338, 406 (4); Pacheco, L.M. 23 (4); Passos, L. 5403 (4); Pastore, J.F.B. 2034 (3); Pinto, G.C.P. 26/81 (4); Popovkin, A.V. 982 (2); Prata, A.P. 1929 (4); Queiroz, L.P. 1015 (4), 2496 (2), 9104, 14735 (4), 14815 (2); Rebouças, P.L.O. 14 (2); Ribeiro, T. 319 (1), 538 (4), Santana, W. s.n. HRB 23366 (4); Silva, U.C.S. 3 (3); Tourinho, R. 31 (4). 